\title{
Ekonomi Berdaulat dan Berkeadilan dalam Perspektif Muhammad Iqbal
}

\author{
Abdullah Firdaus \\ Pascasarjana UIN Sulthan Thaha Saifuddin Jambi \\ Email: abd_firdaus70@yahoo.com
}

\begin{abstract}
Religion is the basic capital in building a solid economy. Social welfare in an Islamic perspective is not only oriented towards fulfilling material needs but must be based on the principle of justice which considers the aspects of material, social and spiritual satisfaction for the individual as well as for the wider community. This paper is intended to explore the thoughts and economic vision initiated by Muhammad Iqbal. This study is a qualitative study using a content-analysis approach through data taken from various writings related to this research. In the end, this research concludes that economic justice will be realized if there is political sovereignty, and political sovereignty will be realized if there is independence. The concept of a just economy is born from religious guidance and teachings because it directly defines the concept of holistic welfare in the vital aspects of human needs.
\end{abstract}

Keywords: Material-spiritual satisfaction, economic justice, holistic welfare, Muhammad Iqbal.

\begin{abstract}
Abstrak: Agama menjadi modal dasar dalam membangun perekonomian yang solid. Kesejahteraan sosial dalam perspektif Islam, tidak hanya berorientasi pada pemenuhan kebutuhan material saja akan tetapi ia harus berlandaskan kepada prinsip keadilan yang mempertimbangkan aspek kepuasan material, sosial dan spiritual bagi individu juga terhadap masyarakat luas. Tulisan ini dimaksudkan untuk mengeksplorasi pemikiran dan visi ekonomi yang digagas oleh Muhammad Iqbal. Kajian ini bersifat kualitatif dengan menggunakan pendekatan contentanalysis melaui data-data yang diambil dari berbagai penulisan yang terkait dengan penelitian ini. Pada akhirnya penelitian ini menyimpulkan bahwa keadilan ekonomi akan terwujud jika ada kedaulatan politik, dan kedaulatan politik akan wujud jika ada kemerdekaan. Konsep ekonomi berkeadilan lahir sesungguhnya dari bimbingan dan ajaran agama karena ia secara langsung mendefinisikan konsep kesejahteran holistik aspek vital kebutuhan manusia.
\end{abstract}

Kata-kata kunci: Kepuasan material-spiritual, ekonomi berkeadilan, kesejahteran holistik, Muhammad Iqbal.

\section{Pendahuluan}

Kolonialisasi yang menciptakan Intimidasi global terhadap negeri jajahan telah meruntuhkan bangunan kehidupan umat manusia. Hal ini sangat dirasakan oleh umat Islam yang tinggal di anak benua India. Terutama getirnya kemiskinan yang semakin memperburuk tatanan kehidupan sosial penduduk muslim anak benua India tersebut. Fenomena ini juga yang 
menginsipirasi Sir Muhammad Iqal untuk merekonsruksi pemahaman terhadap diksi dan mesej agama, termasuk didalamnya adalah persoalan ekonomi umat. Bagi Iqbal Agama menjadi sumber kekuatan dalam berbagai aspek yang digeluti oleh manusia. Sekalipun Iqbal lebih dikenal sebagai penyair yang filosof (a poet-philosopher). Konsep ekonomi yang digagas oleh Iqbal sarat dengan nilai keadilan yang mendefinisikan ekonomi tidak hanya berorentasi pada kesejahteraan secara materi namun lebih jauh kesejahteraan secara mental spiritual yang memartabatkan khudi (Individual) dan Bekhudi (Community and Environtment) secara bersamaan. Konsep ekonomi ini juga pada akhirnya menjadi prinsip dan cikal bakal kebijakan ekonomi Pakistan kelak.

\section{Reformasi Sosial Dan Politik}

Dalam observasi Iqbal, kekisruhan dan ketidakadilan sosial menjadi potret yang lazim mewarnai kehidupan umat Islam secara global. Cepat atau lambat hal ini akan berubah menjadi bencana sosial yang serius, jika tdiabaikan secara terus-menerus. Sekurang-kurangnya ada tiga domain menurut Iqbal yang menjadi penyebab utama kemelut sosial yang menimpa umat Islam, Tiga domain tersebut yaitu:

Pertama. Stagnasi intelektual Kaum Mulla yaitu para ulama semenjak kejatuhan Baghdad. Sehingga golongan ulama menjadi sangat konservatif dan melarang segala aktivitas intelektual (ijtihad). Hal ini sedikit berubah seiring munculnya gerakan Wahabi yang memberi inspirasi bagi pembaharu Islam abad ke-19. Pada awalnya kemunculan gerakan ini sesungguhnya merupakan gerakan kebangkitan yang merespon sikap kaku para ulama. Adapun antara objektif pembaharuan yang mereka bawa, ialah memberikan orientasi baru tentang persoalan keimanan (akidah) dan kebebasan untuk menafsirkan semula hukum Islam (ijtihad) sesuai dengan tuntutan zaman. ${ }^{1}$

Kedua. Distorsi Spiritual Gerakan kerohanian Islam atau tasawuf. Masyarakat Islam dipengaruhi oleh sejenis mistisme yang membutakan diri daripada kenyataan dan melemahkan masyarakat serta membelenggu mereka dalam khurafat. Tasawuf telah jatuh dari derajatnya yang tinggi sebagai kekuatan pendidikan rohani menjadi eksploitasi kejahilan masyarakat yang mudah tertipu. Sehingga umat Islam terjebak dalam pemahaman hukum Islam yang keras dan kaku. Para pembaharu abad ke-19 bangkit menentang bentuk mistisisme yang seperti ini dan mengajak umat Islam menuju dunia modern yang luas dan terang. Sikap ini diambil bukan berarti mereka bersikap materialis, akan tetapi misi para pembaharu ini adalah untuk membuka mata umat Islam agar kemabali kepada (the spirit of Islam) semangat Islam yang bertujuan untuk menyelesaikan permasalahan dan bukan lari daripadanya. ${ }^{2}$ Banyaknya penyelewengan terhadap substansi

1 Syed, A. Vahid, Thoughts and Reflections of Iqbal, hlm. 279; Schimmel, A, Gabriel's Wings: a Study into the Religious Ideas of Sir Muhammad Iqbal, 1963, hlm. 75.

2 Syed, A. Vahid, Thoughts and Reflections of Iqbal, hlm. 279; Schimmel, A, Gabriel's Wings: a Study into the Religious Ideas of Sir Muhammad Iqbal, hlm. 75. 
kerohanian Islam yang seharusnya menjadi kekuatan bagi pembangunan individu dan masyarakat, membuat Iqbal mengkritik praktik zuhud yang diamalkan oleh para sufi dewasa ini yang justeru melemahkan potensi yang ada pada manusia. Sesungguhnya sebagai makhluk sosial, manusia dituntut untuk terus bergerak maju dan berkembang, mengeksplorasi alam semesta. Menurut Iqbal:

Semangat zuhud (asceticism) yang berlebih-lebihan yang dipraktikkan oleh kaum sufi dewasa ini telah mengelabui pandangan mata manusia untuk melihat aspek yang terpenting dalam Islam sebagai politik social. $^{3}$

Zuhud yang bercorak pasif terhadap sisi pergerakan dan perkembangan sosial menjadi ancaman bagi kreativitas berfikir dan semangat ijtihad. Iqbal sebagai seseorang yang berinklinasi sufistik terlihat pada kecintaannya terhadap sosok Jalal al-Din Rumi menjadi bukti kuat mengenai hal itu. Ini menunjukkan bahwa Iqbal sangat memperhatikan bahkan mencintai tasawuf sebagai jalan mengenali diri dan mendekatkan diri kepada Sang Pencipta. Namun corak tasawuf yang diamalkan Iqbal lebih bersifat aktif dalam ranah sosial dengan cara menjadikan aspek spritualitas dalam diri seseorang menjadi hidup dan bergerak dinamis dan progresif dalam kehidupan nyata (actual life). ${ }^{4}$

Gerakan pembaharuan abad 19 bangkit dapat difahami sebagi anti tesis atas corak tasawuf ascetik yang mengkerdilkan peran sosial dalam ranah publik. Gerakan ini bahkan menggiring umat Islam menuju wawasan dunia modern yang menekankan aspek pendekatan empirik dan eksperimental dalam berinteraksi dengan kehidupan ini. Ini bukan berarti menjadikan seorang muslim berubah menjadi materialis. Iqbal mengakui bahwa fenomena kerohanian Islam muncul sebagai sebuah respon terhadap para sarjana hukum Islam yang ketika membincangkan isu hukum Islam cenderung mengabaikan pesan kerohanian dan moral di sebalik hukum itu sendiri. Akibat gersangnya misi moral dalam membincangkan diskursus hukum Islam membuat Sufyan al-Thawri yang meski seorang ahli fiqh lebih memilih untuk hidup secara sufi 5 .

Ketiga. Hedonisme dan Tirani Raja-raja muslim. Iaitu para penguasa dan kepala pemerintahan Islam. Mereka lebih banyak menumpukan parhatian mereka kepada bagaimana menjaga kepentingan keluarga diraja saja. Selama kepentingan ini terjaga, mereka tidak segan untuk menjual negeri mereka kepada pembeli dengan harga tertinggi. Menyikapi hal ini kita dapati bahwa pemikiran yang dibawa Sayyd Jamal al-din al-Afghani adalah

${ }^{3}$ Iqbal, M, The Reconstruction of Religious Thought In Islam, hlm. 178.

4 May, L.S, Iqbal and His Philosophy, dlm. M. Saeed Sheikh (pnyt), Studies in Iqbal's Thought and Art, Bazm-i-Iqbal, Lahore, 1972, hlm. 13.

${ }^{5}$ Iqbal, M, The Reconstruction of Religious Thought In Islam, hlm. 178. 
sebai respon untuk mengkaunter ketidakadilan pemerintah sehingga beliau menyeru umat Islam agar bangkit melawan kezaliman ini. ${ }^{6}$

Jadi dalam pandangan Iqbal tiga elemen yang disebutkan di atas tadi menjadi penyebab utama krisis multidimensional yang mendera umat Islam dewasa ini.

Di sisi lain kenyataan yang dialami oleh umat Islam di tanah India khususnya sangat dilematis dimana hegemoni Barat dengan segala pesona dan kekuatannya telah membutakan generasi muda muslim sehingga mereka menerima begitu saja segala sesuatu yang datang dari Barat tanpa disaring terlebih dahulu. Perkara ini menyusup ke dalam belbagai aspek, seperti aspek pendidikan di yang kental dengan sistem dan konsep sekuler dan materialistis yang jelas mengabaikan nilai-nilai murni agama dan bahkan hanya takluk dalam pengaruh imperialis Barat'.7

Dalam keyakinan Iqbal, agama semestinya menjadi sumber inspirasi dan kekuatan yang seharusnya menaklukkan dunia, teks-teks ayat suci selalu mengaitkan antara daya nalar akal pikiran manusia dengan fenomena alam dan jagat raya. Bahkan Al-Quran lebih banyak menekankan aspek tindakan dan Aksi daripada gagasan (The Qur'an is a book which emphasizes 'deed' rather than 'idea' ${ }^{8}$, begitu menurut Iqbal. Sehingga persoalan aksi menjadi sangat penting untuk merefleksikan sebuah gagasan. Dalam konteks ini dimensi spiritual akan bermakna jika ia dimanifestasikan dalam bingkai kerja sosial.

Menurut Iqbal, aspek spiritual dan sosial pada diri seseorang memiliki hubungan integral antara satu sama lain. Dalam mengimplementasikan konsep tersebut Iqbal membuat langkah-langkah yang dimulai dengan memahami diri sendiri (Khudi) dan masyarakat (Bekhudi), yaitu dengan menajamkan kekuatan intelektual muslim melalui pengenalan atas sejarah dan pengalaman beragama umat Islam terdahulu.

Iqbal mengkritik pedas pengaruh Hindu, pengalaman mistik dan sinkretisme masih sangat dominan mewarnai aspek agama dan sosiokultural umat Islam India. ${ }^{9}$ Bentuk pemahaman Islam yang keliru dan praktek pengamalan ajarannya yang bersifat simbolik dan formalis semakin melebarkan jurang dari tujuan murni dan moderasi yang diajarkan oleh Islam.Secara sarkastik, Iqbal mengomentari fenomena ini:

6 Syed, A. Vahid, Thoughts and Reflections of Iqbal, hlm. 279: Schimmel, A, Gabriel's Wings: a Study into the Religious Ideas of Sir Muhammad Iqbal, hlm. 75.

7 Azizi, Muhammad al-cArabi, Muhammad Iqbal Fikruhu al-Dini wa al-Falsafi, Dar alFikr, Libanon, 1999, hlm. I63.

8 Iqbal, M, 2006, The Reconstruction of Religious Thought In Islam, Master Piece Publication Sdn.Bhd. Kuala Lumpur, hlm. v.

${ }^{9}$ Malik, Hafeez, The Man of Thought and Man of Action, dlm. Malik, Hafeez (pnys), Iqbal Poet-Philosopher of Pakistan, Columbia University Press, New York, 1971, hlm. 70. 
Aku yakin jika Nabi turun kembali dan mengajarkan tentang Islam di negeri ini, tentu mereka tidak lagi mampu memahami kebenaran Islam disebabkan oleh kondisi dan perilaku mereka saat ini. ${ }^{10}$

Pemaparan diatas menjelaskan bahwa domain sosial politik dan kerohanian menjadi agenda vital dalam gagasan pembaharuan Iqbal.

\section{Kebebasan dan Kedaulatan Politik}

Dalam logika Iqbal upaya untuk mengentaskan kemiskinana dan persoalan sosial ekonomi yang mengeluti umat Islam tidak akan pernah terwujud jika tidak ada kedaulatan politik, Dan kedaulatan politik tidak akan pernah terealisasi jika umat Islam tidak merdeka dan bebas dari penjajahan bangsa lain. Ini artinya Kedaulatan ekonomi berbanding lurus dengan kedaulatan politik. Oleh sebab itu, menurut Iqbal umat Islam India sudah semestinya memiliki suatu wilayah tertentu untuk menentukan nasib mereka sendiri. Pernyataan ini secara tegas disampaikan Iqbal dalam sidang paripurna di depan anggota perhimpunan Liga Muslim India (All-India Muslim League) di Allahabad 1930. Iqbal menyarankan dibentuknya sebuah negara untuk umat Islam India yang terpisah dan mandiri.

Aku sangat ingin melihat Punjab, Provinsi sempadan Barat Daya, Sind dan Baluchistan menjadi sebuah negara, memiliki pemerintahan sendiri sama ada di dalam empayar British ataupun di luar empayar British. terbentuknya negara India muslim di Barat Daya bagi ku merupakan ketentuan akhir bagi nasib umat muslim, sekurang-kurangnya di Barat Daya India. ${ }^{11}$

Konsep kebebasan berpolitik dan berdaulat secara ekonomi yang terus didengunkan oleh Iqbal telah mengilhami pemuda muslim India untuk berjuang memerdekakan diri belenggu imperialisme Barat dan menjadi referensi sejarah terbentuknya negara Pakistan.

Berkenaan dengan kemelut ekonomi dan kemiskinan yang mendera uamat Islam anak benua India. Iqbal mengutarakan pandangannya bahwa satu-satunya solusi untuk ini semua adalah berdirinya tanah air yang merdeka untuk umat muslim India.. Pada 28 Mei 1937, sebelum ajala menjmputnya Iqbal sempat menulis: hlm. 74.

${ }^{10}$ Schimmel, A, Gabriel's Wings: a Study into the Religious Ideas of Sir Muhammad Iqbal,

${ }^{11}$ Syed, Abdul Vahid, Thoughts and Reflections of Iqbal, Lahore: Sh. Muhammad Ashraf, 1964, hlm. 171. 
"The problem of bread is becoming more and more acute" (persoalan roti (pangan) semakin akut. Umat Islam mulai merasakan keterpurukan yang semakin menjadi-jadi sejak 200 tahun ini. ${ }^{12}$

Iqbbal percaya bahwa kemiskinan yang mendera umat Islam India diakibatkan dua hal yang krusial pertama pola rentenir dalam praktek injaman uang yang dilakukan oleh orang Hindu ataupun, kedua imperilisme Barat terhadap umat Islam.

Risalah Iqbal untuk mewujudkan negara yang merdeka, hak untuk menentukan nasib sendiri (national self determination) terus menginspirasikan jutaan umat muslim India. Slogan 'Le Kae Rahain Gae Pakistan' (Kita harus memenangkan Pakistan!), terus menggelorakan semangat umat muslim India dari Khayber sampai ke Cape Camorin. Sehingga akhirnya pada pilihan raya 1946, Liga Muslim menang sebulat suara. Sebuah kemenangan dicapai, yang akhirnya menghantarkan lahirnya Negara Islam Pakistan pada 14 ogos 1947. Meski semasa hidupnya, Iqbal tidak pernah sempat menyaksikan; lahirnya Negara Islam merdeka yang beliau impikan tersebut. 13

Untuk merealisasikan itu semua, dalam pandangan Iqbal perlu meletakkan agama dan negara, keyakinan dan kekuasaan politik dalam satu ruang yang sama sehingga agama dan negara berintegarasi antara satu dengan yang lain. Jika sebuah kepercayaan (faith) tidak disokong oleh kebijakan aktual negara, maka agama menjadi falsafah yang hanya wujud dalam wilayah akal dan logika belaka. Fakta ini sangat diyakini oleh Iqbal. Sehubungan dengan ini Iqbal menyatakan:

Agama tanpa kekuasaan hanyalah falsafah. Ini merupakan wacana yang tepat. Gagasan itu mendorongku untuk menuliskan mathnawi kebenaran ini. ${ }^{14}$

Agama memerlukan negara untuk menerapkan ajaran-ajaranya, dan negara memerlukan agama untuk membimbingnya. Dalam konteks ini politik dan negara adalah ibarat sebuah satu sukatan yang berintegrasi dengan agama. Secara falsafah, teori politik Islam yang digagas oleh Iqbal bersifat normatif. Ia bertumpu kepada cita-cita etik yang khas yakni mengangkat umat manusia menuju kewujudan tertinggi secara moral maupun material yang berdasarkan kepada ketundukan kepada Tuhan Yang Maha Esa ${ }^{15}$. Iqbal juga menegaskan bahwa:

12 Allama Iqbal menuli 13 pucuk surat kepada Muhammad Ali Jinnah, empat kali di Tin 1936 dan sembilan kali pada tahun 1937 , Letters of Iqbal to Jinnah, Lahore: Sh. Muhammad Ashraf, 1974, hlm. 17.

13 Riaz Hussain, The Politics f Iqbal, Lahore: Islamic Book Service, 1977, hlm. 106.

14 Schimmel, Annemarie, Gabriel's Wing a study into the religious ideas of Sir Muhammad Iqbal, Leiden: E.J Brill, 1963, hlm. 42.

15 Ahmad, Muhammad Aziz, Iqbal and The Recent Exposition of Islamic Political Thought, Lahore: Sh, Muhammad Ashraf, 1965, hlm. 3. 
Al-Qur'an memandang perlu menggabungkan antara agama dan negara, etika dan politik dalam satu bingkai wahyu'16 Oleh sebab itu dalam persepsi Iqbal, Islam bukan sekedar agama atau nama sebuah keyakinan atau sebuah bentuk ritual saja. Agama sesungguhnya adalah sebuah ideologi hidup, sebagai falsafah hidup yang mempunyai seperangkat aturan yang berakar dalam emosi manusia secara mendalam. Ia memberi arahan dan bimbingan manusia semenjak daripada buaian sehingga ke liang kubur dari alam kubur hingga ke alam akhirat. Menurut Iqbal Islam merangkumi berbagai aspek hidup manusia. Pendek kata agama berorientasi kepada peningkatan kualitas hidup manusia secara keseluruhan termasuk di dalamnya isu tentang ekonomi. Menurut Iqbal

Islam lebih daripada sekadar akidah, ia juga bererti sebuah ummat, sebuah negara. Keanggotaan Islam sebagai sebuah millat tidak ditentukan oleh tempat kelahiran, letak seseorang ataupun kedudukannya. Ia terwujud dalam sebuah identiti keyakinan. Ungkapan 'umat Islam India', meski terasa nyaman didengar oleh telinga. Namun hal ini bercanggah dengan istilah yang dimaksud. Islam pada hakikatnya di atas segala keadaan ruang tempat dan masa. Kebangsaan bagi kita merupakan sebagai gagasan murni, dan bukan berdasarkan letak geografi. ${ }^{17}$

Dalam Islam menurut Iqbal lagi 'negara, millat, imam, individu dan pemerintah tidak boleh ada dikotomi dan sekat yang memisahkan kedua aspek tersebut. Begitupula dengan pelbagai aspek kehidupan seseorang yang berkenaan dengan aspek sosial, agama, politik dan ekonomi, ia juga tidak dapat dipisah-pisahkan antara satu sama lain ${ }^{18}$. Dalam artikel The Muslim Community, Iqbal mengatakan bahwa:

Objektif agama bukanlah hanya memikirkan isu tentang hidup saja. Tujuan utama agama ialah bagi membangun masyarakat sosial yang selaras bagi menaikkan taraf kehidupan secara berangsur-angsur' to build up a coherent social whole for the gradual elevation of life. ${ }^{19}$

Bagi Iqbal agama berfungsi untuk menumbuhkan perkembangan seseorang sama ada dari aspek moral maupun dari aspek material, maju

16 Iqbal, The Reconstruction of Religious Thought In Islam', Malaysia: Master Piece, 2006, hlm.193, lihat juga Ahmad, Muhammad Aziz. 1965. Iqbal and The Recent Exposition of Islamic Political Thought, Lahore: Sh. Muhammad Ashraf, hlm. 5.

17 Syed, Abdul Vahid, Thoughts and Reflections of Iqbal, Lahore: Sh.Muhammad Ashraf, 1964, hlm. 50 - 51.

18 Muhammad Aziz Ahmed, Iqbal and The Recent Exposition of Islamic Political Thought, Lahore: Sh. Muhammad Ashraf, 1965, hlm. 4 - 5.

19 Latif Ahmed Sherwani, Speeches, Writings, Statements of Iqbal, Lahore: Iqbal Academy, 1977, hlm.105; Syed, Abdul Vahid, Thoughts and Reflections of Iqbal, Lahore: Sh.Muhammad Ashraf, 1964, hlm. 378. 
secara spiritual dan intelektual maju pula secara politik, ekonomi dan sosial melalui bimbingan wahyu. Ini kerana hakikat agama adalah sebuah keyakinan yang bertujuan 'untuk mentransformasi dan membimbing perkembangan dalaman dan luaran seseorang'. ${ }^{20}$ Objektif hidup itu sendiri adalah untuk mewujudkan dan menyempurnakan diri individu berlandaskan kepada pengembangan potensi yang dimilikinya sesuai dengan petunjuk agama. Al-Quran memandang bahawa sangat penting untuk menyatukan agama dan negara, etika dan politik dalam bingkai wahyu, persis sebagaimana yang dilakukan oleh Plato dalam Republic-nya'21

\section{Perubahan Sosial Ekonomi}

Substansi ajaran agama selaras dan akomodatif terhadap fenomena pergerakan umat manusia yang bersifat dinamis dan progresif. Ini artinya agama meletakkan prinsip-prinsip umum sebagai dasar untuk menata kelola berbagai kebutuhan dan kecenderungan umat manusia, Hal ini sangat disadari oleh Iqbal bahwa agama mengarahkan penganutnya untuk tidak pasif namu secara progresif berubah ke arah yang lebih baik. Oleh sebab itu Iqbal meyakini bahwa melakukan perubahan terhadap aspek sosial-ekonomi menjadi sangat penting demi untuk membangun keadilan sosial. Sebagai contoh ketika berbicara tentang isu perniagaan sebagai sendi ekonomi, tidak cukup jika ia hanya difokuskan kepada sebesar apa keuntungan yang akan diperoleh dengan mengabaikan pihak-pihak tertentu yang menjadi mitra perdagangan tersebut. Namun sistem perniagaan ini haruslah berpijak pada landasan etika teologis yang menjunjung tinggi nilai-nilai kemanusian seperti kejujuran, transparansi, amanah dan berlaku adil.

Konsep perniagaan seperti ini diketengahkan oleh Iqbal dalam tiga pernyataan beliau pada rapat anggaran di depan para anggota Dewan Legislatif Punjab pada 28 Februari 1928 beliau mengkritik ketidakseimbangan kebijakan penerapan pajak pendapatan. Antara besaran jumlah pajak yang dikenakan keatas pemilik tanah berbeda dengan apa yang diterapkan ke atas pekerja. Dimana pekerja buruh membayar pajak lebih dari pemilik tanah atau usaha. Disamping itu juga beliau mengusulkan pentingnya pemerintah memperhatikan pengadaan dana untuk sanitasi penduduk desa dan kesehatan wanita. Visi ekonomi yang digagas Iqbal ini tujuannya adalah untuk menghindari eksploitasi kapitalis para kaum pemodal atas rakyat yang dipekerjakan yang menjadi sumber pendapatan mereka ${ }^{22}$. Perubahan terkait kebijakan pajak penghasilan dan pendapatan dibawah prinsip keadilan ini menjadi strategi penting dalam visi ekonomi Iqbal.

20 Iqbal, The Reconstruction of Religious Thought in Islam, Malaysia: MasterPiece Publications SDN.BHD, 2006, hlm. 4.

21 Iqbal. The Reconstruction of Religious Thought in Islam, Malaysia: MasterPiece Publications SDN.BHD, 2006, hlm. 193.

22 Syed, Abdul Vahid, Thoughts and Reflections of Iqbal, Lahore: Sh. Muhammad Ashraf, 1964, hlm. 311. 
Dalam hal ini mantar Mantan Wakil Rektor Universitas Punjab sekaligus pakar ekonomi Dr Rafiq Ahmad menyampaikan pernyataan beliau ketika menyampaikan ceramah tentang Pandangan Ekonomi Iqbal, yang diadakan oleh Yayasan Nazaria-i-Pakistan dan Asosiasi Pekerja Pakista sehungungan peringatan hari lahir Iqbal yang ke 125:

"Iqbal secara umum lebih dikenali sebagai penayai yang filosof Iqbaldan juga pemikir politik namun buku pertama beliau Ilmul Iqtisad mengandung gagasan ekonomi yang revolusioner, yang selanjutnya mengjewantah pada kegiatan Iqbal pada hari-hari berikutnya. Ketikan bergelut dalam dunia politik sebgai anggota Dewan Legislatif Punjab. Iqbal menegaskan bahwa penyebab utama kemiskinan yang mendera umat Islam India adalah akibat penyewa yang tidak memiliki tanah dan pekerja dimana perputaran uang dikendalikan sepenuhnya oleh pemilik modal. Iqbal bepandangan bahwa Kaum berjouis orang yang egois yang hanya mengeksploitasi orang miskin. ${ }^{23 "}$

Dikarenakan kemajuan ekonomi berhubungan dengan pembangun sosial Untuk mencapai kemajuan ekonomi Iqbal meletakkkan tiga prinsip dasar:

1. Memiliki ilmu pengetahuan dan Keterampilan Kerja

2. Mewujudkan keluarga berencana

3. Menghapus egosentrisme ekonomi yang menjadi penyebab ketidakadilah ekonomi ditengah masyarakat dengan mengedepankan semangat untuk mengorbankan kepentingan pribadi demi kepentingan publik. ${ }^{24}$

Dalam waktu yang sama, Iqbal menegaskan bahwa implemtentasi perubahan yang dimaksud sangat bergantung kepada kesempurnaan moral seseorang (the moral perfection of man) sebagai agen perbahan ketika mana Islam menjadi pengendalinya: 25

Apa yang mereka dengungkan sebaga perniagaan, hakikanya hanyalah permainan dadu, bagi seseorang menjadi sebuah keuntungan dan bagi jutaan orang adalah kematian yang memilukan Sains, Filasat, kaum cendekia, pemerintah berkhutbah tentang kualitas manusia, Namun pada saat yang sama, mereka minum darah manusia. ${ }^{26}$

${ }^{23}$ Dr, Rafik Ahmad, 2002 Iqbal against concentrations of wealth in few hands, https://www.dawn.com/news/65437/iqbal-against-concentration-of-wealth-in-fewhands.

24 Dr, Rafik Ahmad, 2002 Iqbal against concentrations of wealth in few hands, https://www.dawn.com/news/65437/iqbal-against-concentration-of-wealth-in-fewhands.

25 Shamloo, Speech on the Budget 1930-31, yang disampaikan dihadapan Dewan Legislatif Punjab, pada 7 Maret 1930, hlm. 87-88.

${ }^{26}$ L. R. Gordon Polonskaya, 8Ideology of Muslim Nationalism, dalam Iqbal a poetphilosopher of Pakistan, Hafeez Malik (pnyt), New York: Columbia University Press, 1971. 


\section{Strategi Sosial Budaya dan Ekonomi}

Untuk mengkristalisasi sebuah konsep ke dalam dunia realitas tidak cukup dengan sosialisasi wacana ditengah publik. Hal ini sangat diakui oleh Iqbal, oleh sebab itu beliau merumuskan kerangka kerja yang lebih bersifat operasioanal dan aktual sebagai strategi untuk mencapai tujuan bersama umat Islam India dalam meraih kemerdekaan dan kedaulatn mereka dalam segala bidang. Dalam hal ini Iqbal melansir lima poin rancangan kerja umat dalam sidang paripurna di Lahore pada 21 Maret 1932, yaitu:

(1) Umat Islam harus memiliki afiliasi dan berperan aktif dalam berbagai organisasi politik baik di tingkat provinsi ataupun wilayah di seluruh India.

(2) Mendesak dan merekomendasikan para anggota dewan agar menaikkan dana negara bagi organisasi politik umat Islam.

(3) Membentuk Sayap Pemuda yang didukung oleh para sukarelawan di segeanp negeri dibawah bimbingan dan kendali dewan organisasi pusat.

(4) Menciptakan Lembaga Budaya Bagi Pria dan Wanita di setiap pelosok Kota Besar India (British India).

(5) Membentuk Perhimpunan Ulama (an assembly of ulema) termasuk didalamnya Pengacara Muslim yang kompeten dalam bidang hukum Islam modern. ${ }^{27}$

Selain dari langkah politis dan kerangka strategis yang dikonsepksikan oleh Iqbal, sebagai sesorang yang visioner dan futuristik, Iqbal juga banyak menyuarakan konsep tatanan ekonomi baru yang lebih adil dan mensejahterakan tidak eksploitatif sebagaimana praktik ekonomi yang diterapkan oleh Imperialis Barat terjadpa bang Timur.diaman dominasi ekonomi dan hegemoni politik mereka telah menimbulkan bencana sosial dikalangan bangsa Timur. Dalam puisinya Iqbal mengkritik tajam kolonialisasi Barat atas bang Asia. Dalam hal ini Iqbal menulis:

Aku menetang nasionalisme sebagaiman yang dipahami oleh Bangsa Eropa,

Bukan karena hal ini bisa dikembangkan di India

Akan tetapi karena tidak memmberi keuntungan secara material bagi umat Islam

Aku melawan itu semua karena aku melihat butir-butir materialisme yang ateistik Yang dalam pandangan $\mathrm{ku}$ ia merupakan bahaya yang besar untuk umat manusia modern. ${ }^{28}$

${ }^{27}$ L. R. Gordon Polonskaya 1971 8Ideology of Muslim Nationalism, dalam Iqbal a poetphilosopher of Pakistan, Hafeez Malik (pnyt) hlm. 113, New York: Columbia University Press: Shamloo, Speech on the Budget 1930-31, yang disampaikan didepan Dewan Legislatif Punjab, pada 7 Maret 1930, hlm. 92. 


\section{Penutup}

Beberapa kesimpulan yang dapat ditarik dari uraian di atas, yaitu:

1. Iqbal yang lebih dikenal sebagai penyair yang filosof mempunyai pandangan ekonomi yang unik yang direfleksikan dalam buku Ilmul Iqtisad berbahasa Urdu.

2. Pembangunan sosial sangat berkaitan dengan kesejahteran ekonomi masyarakat

3. Kapitalisme menjadi ancaman terhadap pembedayaan ekonomi masyarakat

4. Kedaulatan ekonomi berbanding lurus dengan kedaulatan politik. Kedaulatan politik hanya akan terwujud jika satu negara itu merdeka.

5. Konsep dan visi ekonomi yang digagaskan oleh Iqbal, lebih bersifat humanistik yang tidak hanya mementingkan aspek kemakmuran secara material saja akan tetapi juga bernilai spiritualistik yang bersenyawa dengan ajaran dan tuntunan agama.

6. Isu kemiskinan, ketidakadilan serta pemerataan sosial secara ekonomi menjadi topik utama dalam gagasan ekonomi Iqbal.

7. Dasar Tawhid menjadi landasan yang sangat penting dalam konsep pembanguna ekonomi dan sosial.

\section{Bibliografi}

Gordon, P.L.R. 1971. Ideology of Muslim Nationalism. Dlm. Malik, Hafeez (pnyt). Iqbal: Poet-Philosopher of Pakistan. New York: Columbia University Press

Hafeez Malik (pnyt). 1971. Iqbal: Poet-Philosopher of Pakistan. New York: Columbia University Press.

Iqbal, Muhammad. 2006. The Reconstruction of Religious Thought in Islam. Selangor: Masterpiece Publications Sdn. Bhd.

May, L.S. 1972. Iqbal and His Philosophy. Dlm. M. Saeed Sheikh (Pnyt). Studies in Iqbal's Thought and Art. hlm. 1-30. Lahore: Bazm-i-Iqbal.

Sherwani, Latif Ahmed (pnyt). 1977. Speeches, Writtings and Statements of Iqbal. Lahore: Iqbal Academy Pakistan.

Sheikh, M. Saeed (pnyt). 1972. Studies in Iqbal's Thought and Art. Lahore: Bazm-i Iqbal Club Road.

28 Sherwani, Latif Ahmed, 1977, Speeches, Writings, And Statements of Iqbal, Presidential Address Delivered at the Annual Session of the All-IndiaMuslim League at Allahabad on December 29, 1930, hlm. 28. 
Syed, Abdul Vahid. 1969. Thoughts and Reflections of Iqbal. Lahore: SH. Muhammad Ashraf.

Dr, Rafik Ahmad, 2002 Iqbal against concentrations of wealth in few hands, https://www.dawn.com/news/65437/iqbal-against-concentration-ofwealth-in-few-hands 